\title{
TRAUMATIC BRAIN INJURY
}

\section{NEUROLOGICAL DETERIORATION AFTER MILD TBI}

Investigators from UMDNJ-New Jersey Medical School, Newark, NJ, studied the cause, course, and outcomes of 757 patients who were admitted over 54 months following mild head injury (MHI) complicated by intracranial hemorrhage (ICH). Of these, 31 (4.1\%) experienced delayed neurological deterioration (DND)(Glasgow Coma Scale score decrease $>2$ ); $87 \%$ deteriorated within 24 hours of admission, $68 \%$ had progressive ICH, $32 \%$ had medical causes for DND, and $23 \%$ died. Factors associated with mortality included age $>60$ years, coagulopathy, and change in Marshall CT classification. In adolescents and adults the incidence of DND is low but carries significant morbidity and mortality if it results from progressive ICH. (Choudhry OJ, et al. Delayed neurological deterioration after mild head injury: Cause, temporal course, and outcomes. Neurosurgery 2013 Nov;73(5):753-60).

COMMENTARY. This study shows that the majority (96\%) of adult and adolescent patients with mild head injury plus ICH has a good prognosis and remains stable without neurological decline. In the $4 \%$ with delayed neurological deterioration, $87 \%$ deteriorated within the first 24 hours, mainly because of a progressive $\mathrm{ICH}$. Coagulopathy is an important risk factor and the diagnosis and correction during transmission to a trauma center improves prognosis [1]. Since age ( $>60$ years) is found to be a risk factor [2], children and adolescents may be expected to carry a low risk of delayed neurological deterioration. The following study, however, emphasizes a residual cognitive disability in TBI children aged 7-18 years.

Residual Cognitive Disability in Children with TBI. On admission to inpatient rehabilitation, patients with TBI had more cognitive disability than those with other injuries, and TBI patients had significant residual cognitive disability on discharge [3].

\section{References}

1. Brown CV, et al. Am Surg. 2012 Jan;78(1):57-60.

2. Mosenthal AC, et al. J Trauma. 2004 May;56(5):1042-8.

3. Zonfrillo MR, et al. J Pediatr. 2014 Jan;164(1):130-5.

\section{HYPOPITUITARISM, A SEQUEL TO TBI}

Investigators at Cincinnati Children's Hospital, $\mathrm{OH}$, studied the prevalence of hypopituitarism in children with inflicted traumatic brain injury. Of 14 patients evaluated, $86 \%$ had at least one endocrine dysfunction, and $50 \%$ had 2 or more, a significant increase compared to the general population, estimated to have $2.5 \%$ with endocrine abnormality. Elevated prolactin occurred in $64 \%$, abnormal thyroid in $33 \%$, short stature $(29 \%)$, and low nocturnal growth hormone peak (17\%). A child with a history of inflicted TBI should be followed closely for growth velocity and pubertal changes. If growth velocity is slow, prolactin level and full endocrine evaluation are indicated. (Auble BA, Bollepalli S, Makoroff K, et al. Hypopituitarism in pediatric survivors of inflicted traumatic brain injury. J Neurotrauma 2013 Nov 23). 